\title{
Effects of seeding density and nitrogen fertilizer level on growth and yield of MT10 rice in Ninh Thuan
}

Tieu V. Phan*, Tinh T. Le, Phuoc V. Pham, Kien C. Phan, Thu M. Vo, Nhan T. Nai, Ty Do, Ty Q. Pham, \& Lieu T. Nguyen

Nha Ho Research Institute for Cotton and Agricultural Development, Ninh Thuan, Vietnam

\author{
ARTICLE INFO \\ Research Paper \\ Received: July 20, 2017 \\ Revised: December 26, 2017 \\ Accepted: June 06, 2018 \\ Keywords \\ MT10 rice variety \\ Nitrogen fertilizer dosage \\ Seeding density

\section{${ }^{*}$ Corresponding author} \\ Phan Van Tieu \\ Email: tiendatbv@yahoo.com
}

\begin{abstract}
The experiment was conducted to determine seeding density and nitrogen fertilizer doses for the MT10 rice variety grown in the winter-spring crop 2015/2016 and the Summer-Autumn crop 2016 in Ninh Thuan. Both experiments were established using a randomized complete block design with three replications. The seeding density experiment was performed in winter-spring season $2015 / 2016$, including density levels of 120, 160, 200 and $250 \mathrm{~kg} / \mathrm{ha}$. The nitrogen fertilizer dosage experiment was organized in summer 2016, including 4 levels of 100, 120, 140 and $160 \mathrm{~kg} \mathrm{~N} / \mathrm{ha}$. Other non-experimental elements were identical. The results showed that the highest yield and economic efficiency were for the treatments of 200 $\mathrm{kg}$ seed/ha with a nitrogen fertilizer dose of $140 \mathrm{~kg} \mathrm{~N} / \mathrm{ha}$.
\end{abstract}

Cited as: Phan, T. V., Le, T. T., Pham, P. V., Phan, K. C., Vo, T. M., Nai, N. T., Do, T., Pham, T. Q., \& Nguyen, L. T. (2018). Effects of seeding density and nitrogen fertilizer level to growth and yield of MT10 rice in Ninh Thuan. The Journal of Agriculture and Development 17(5), 47-52. 


\title{
Ảnh hưởng của mật độ sạ và liều lượng phân đạm đến sinh trưởng và năng suất giống lúa MT10 tại Ninh Thuận
}

\author{
Phan Văn Tiêu*, Lê Trọng Tình, Phạm Văn Phước, Phan Công Kiên, Võ Minh Thư, \\ Nại Thanh Nhàn, Đỗ Ty, Phạm Quốc Tý \& Nguyễn Thị Liễu \\ Viện Nghiên Cứu Bông và Phát Triển Nông Nghiệp Nha Hố, Ninh Thuận
}

\author{
THÔNG TIN BÀI BÁO \\ Bài báo khoa học \\ Ngày nhận: 20/07/2017 \\ Ngày chỉnh sưa: 26/12/2017 \\ Ngày chấp nhận: 20/06/2018 \\ Từ khóa \\ Giống lúa MT10 \\ Liều lượng phân đạm \\ Mật độ sạ \\ *Tác giả liên hệ \\ Phan Văn Tiêu \\ Email: tiendatbv@yahoo.com
}

\section{TÓM TẮT}

Thí nghiệm xác định mật độ sạ và liều lượng phân đạm thích hợp cho giống lúa MT10 tại Ninh Thuận được thực hiện trong vụ Đông Xuân 2015/2016 và vụ Hè Thu 2016. Cả hai thí nghiệm được bố trí theo kiểu khối đầy đủ ngẫu nhiên (RCBD); thí nghiệm mật độ sạ bố trí vụ Đông Xuân 2015/2016, gồm 4 mức mật độ $120,160,200$ và $250 \mathrm{~kg} / \mathrm{ha}$; thí nghiệm phân đạm bố trí vụ Hè Thu 2016, gồm 4 mức 100, 120, 140 và $160 \mathrm{~kg} \mathrm{~N} /$ ha; các yếu tố phi thí nghiệm khác đồng nhất. Kết quả đã xác định được: trong điều kiện sản xuất giống MT10 tại Ninh Thuận, mật độ sạ thích hợp là $200 \mathrm{~kg}$ giống/ha và liều lượng phân bón đạm thích hợp là $140 \mathrm{~N} \mathrm{~kg} / \mathrm{ha}$.

\section{1. Đặt Vấn Đề}

Trong sản xuất lúa, để tăng năng suất và hiệu quả sản xuất, ngoài sử dụng giống lúa mới năng suất cao, thì các biện pháp kỹ thuật canh tác là yếu tố quyết định đến sự sinh trưởng, phát triển, khả năng chống chịu sâu bệnh và năng suất của cây lúa. Vì vậy, việc xác định các biện pháp kỹ thuật thâm canh, đặc biệt là nghiên cứu lượng giống gieo sạ và lượng phân bón cho cây lúa nhằm nâng cao năng suất, tăng hiệu quả sử dụng phân bón là rất cần thiết (Tran, 2015).

Giống lúa MT10 có thời gian sinh trưởng 95110 ngày, dạng hình gọn, đẻ nhánh khá, chịu thâm canh, phù hợp với nhiều chân đất, cứng cây chống đổ ngã tốt, kháng được sâu bệnh, đặc biệt đối với rầy nâu và đạo ôn; đạt năng suất bình quân khoảng 7 tấn/ha. Giống MT10 đã được Bộ Nông nghiệp và PTNN công nhận giống sản xuất thử vào năm 2014 tại Quyết định số 109/QĐ-TTCLT ngày 04/4/2014 (MARD, 2014). Qua kết quả khảo nghiệm cơ bản trong vụ Đông Xuân
2014/2015 và Hè Thu 2015; kết quả khảo nghiệm sản xuất trong vụ Đông Xuân 2015/2016 và Hè Thu 2016 tại các địa bàn sản xuất lúa trọng điểm của tỉnh Ninh Thuận cho thấy, MT10 là giống lúa rất thích hợp với điều kiện sinh thái của Ninh Thuận, có tiềm năng năng suất cao. Nhằm góp phần đưa giống MT10 vào sản xuất và làm đa dạng cơ cấu giống lúa tại Ninh Thuận, chúng tôi tiến hành nghiên cứu xác định mật độ gieo sạ và lượng phân đạm phù hợp cho giống MT10 tại Ninh Thuận.

\section{Vật liệu và Phương Pháp Nghiên Cứu}

\subsection{Thời gian và địa điểm}

Thời gian: Vụ Đông Xuân 2015/2016 và vụ Hè Thu năm 2016.

Địa điểm: tại xã Nhơn Sơn, huyện Ninh Sơn, tỉnh Ninh Thuận. 


\subsection{Vật liệu thí nghiệm}

Giống lúa MT10: sử dụng giống xác nhận, tỷ lệ nảy mầm $80 \%$.

Các loại phân bón đa lượng: Ure, supe lân, kaliclorua.

\subsection{Nội dung và phương pháp bố trí thí nghiệm}

\subsubsection{Nghiên cứu xác định mật độ sạ phù hợp cho giống lúa MT10}

Thí nghiệm được bố trí theo kiểu khối hoàn toàn ngẫu nhiên (RCBD), 4 nghiệm thức (mật độ sạ), 3 lần lặp lại, diện tích mỗi ô $20 \mathrm{~m}^{2}$, khoảng cánh giữa các ô trong cùng lần lặp lại là $20 \mathrm{~cm}$ và giữa các lần lặp là $30 \mathrm{~cm}$.

Nghiệm thức 1: Gieo sạ với lượng giống 120 $\mathrm{kg} / \mathrm{ha}$.

Nghiệm thức 2: Gieo sạ với lượng giống 160 $\mathrm{kg} / \mathrm{ha}$.

Nghiệm thức 3: Gieo sạ với lượng giống 200 $\mathrm{kg} / \mathrm{ha}$.

Nghiệm thức 4: Gieo sạ với lượng giống 250 $\mathrm{kg} / \mathrm{ha} \mathrm{(d/c).}$

\subsubsection{Xác định liều lượng phân bón đạm thích hợp} cho giống MT10

Thí nghiệm được bố trí trên nền phân $60 \mathrm{P}_{2} \mathrm{O}_{5}$ + $70 \mathrm{~K}_{2} \mathrm{O}$, theo kiểu RCBD, 4 nghiệm thức phân bón, 3 lần lặp lại, diện tích mỗi ô $20 \mathrm{~m}^{2}$, khoảng cánh giữa các ô trong cùng lần lặp lại là $20 \mathrm{~cm}$, và giữa các lần lặp là $30 \mathrm{~cm}$. Cấy 01 dảnh, mật độ cấy: 50 khóm $/ \mathrm{m}^{2}$; tuổi mạ: 11 ngày.

Nghiệm thức 1: Bón $100 \mathrm{~N}$.

Nghiệm thức 2: Bón 120 N (đ/c).

Nghiệm thức 3: Bón $140 \mathrm{~N}$.

Nghiệm thức 4: Bón 160 N.

\subsection{Chỉ tiêu và phương pháp đánh giá}

Chỉ tiêu theo dõi, đánh giá theo tiêu chuẩn Ngành số 10 TCN 216 - 2003.

Các chỉ tiêu cấu thành năng suất: Số bông $/ \mathrm{m}^{2}$, số hạt chắc/bông, khối lượng 1.000 hạt.

Năng suất lý thuyết và năng suất thực thu.

Tình hiệu quả kinh tế.

\subsection{Phương pháp xử lý số liệu}

Tổng hợp số liệu bằng chương trình Excel, phân tích bảng Anova số liệu bằng phần mềm thống kê sinh học MSTATC.

\section{Kết Quả và Thảo Luận}

\subsection{Xác định mật độ gieo sạ thích hợp cho giống lúa mới MT10}

Mật độ gieo sạ là yếu tố có ảnh hưởng lớn đến các yếu tố cấu thành năng suất, đặc biệt là cơ sở cho việc hình thành số bông trong quần thể (Tran, 2015). Mật độ gieo cấy lúa thay đổi tùy theo giống lúa, điều kiện đất đai, thời tiết, lượng phân bón, nhất là phân đạm và chế độ nước (Nguyen, 2008).

\subsection{1. Ảnh hưởng của mật độ sạ đến yếu tố cấu thành năng suất và năng suất}

Kết quả bảng 1 cho thấy số bông hữu hiệu $/ \mathrm{m}^{2}$ của các công thức dao động từ 410,3 - 605,3 bông $/ \mathrm{m}^{2}$. Công thức gieo sạ với lượng $120 \mathrm{~kg}$ có số bông hữu hiệu thấp nhất $\left(410,3 \mathrm{bông} / \mathrm{m}^{2}\right)$, công thức gieo $250 \mathrm{~kg}$ giống/ha có số bông hữu hiệu $/ \mathrm{m}^{2}$ đạt cao nhất, sự sai khác này có ý nghĩa ở độ tin cậy $95 \%$. Kết quả này cũng phù hợp với kết quả nghiên cứu của Nguyen (2006), Doan (2014) \& Tran (2015) "lượng giống gieo sạ tăng làm số bông $/ \mathrm{m}^{2}$ tăng". Tuy nhiên, khi số bông $/ \mathrm{m}^{2}$ tăng quá cao thì bông lúa sẽ bé đi, số hạt/bông giảm và tỷ lệ hạt chắc/bông cũng giảm theo. Để đảm bảo năng suất cao cần điều khiển sao cho ruộng lúa có số bông $/ \mathrm{m}^{2}$ tối ưu, đảm bảo số hạt/bông nhiều, tỷ lệ hạt chắc cao.

Trong điều kiện gieo vụ Đông Xuân, giống lúa mới MT10, sạ với mật độ $120 \mathrm{~kg} / \mathrm{ha}$ có số hạt chắc/bông cao nhất đạt 136,5 hạt/bông, sai khác có ý nghĩa so với các công thức khác. Công thức gieo sạ $250 \mathrm{~kg} / \mathrm{ha}$ cho số hạt chắc/bông thấp nhất, chỉ đạt 96,8 hạt.

Khối lượng 1.000 hạt: Mật độ gieo sạ khác nhau không làm ảnh hưởng tới khối lượng 1.000 hạt. Khối lượng 1.000 hạt của các công thức gieo sạ với mật độ khác nhau không sai khác nhau, đạt từ 25,1 - 25,2 g/1.000 hạt.

Năng suất lý thuyết của công thức gieo $200 \mathrm{~kg}$ giống/ha có năng suất lý thuyết đạt cao nhất, sai khác có ý nghĩa so với các công thức khác. Đây cũng là công thức cho năng suất thực thu cao nhất (Bảng 1). 
Bảng 1. Ảnh hưởng của mật độ sạ đến yếu tố cấu thành năng suất và năng suất của giống MT10, vụ Đông Xuân 2015/2016 tại Ninh Sơn ${ }^{1}$

\begin{tabular}{lccccc}
\hline Nghiệm thức & $\begin{array}{c}\text { Số bông/m } \\
\text { (bông) }\end{array}$ & $\begin{array}{c}\text { Số hạt chắc/bông } \\
\text { (hạt) }\end{array}$ & $\begin{array}{c}\text { Khối lượng 1.000 hạt } \\
(\text { gam })\end{array}$ & $\begin{array}{c}\text { NSLT } \\
\text { (tấn/ha) }\end{array}$ & $\begin{array}{c}\text { NSTT } \\
\text { (tấn/ha) }\end{array}$ \\
\hline $120 \mathrm{~kg} / \mathrm{ha}$ & $410,3^{\mathrm{d}}$ & $136,5^{\mathrm{a}}$ & 25,2 & $14,1^{\mathrm{c}}$ & $7,6^{\mathrm{c}}$ \\
$160 \mathrm{~kg} / \mathrm{ha}$ & $483,7^{\mathrm{c}}$ & $129,2^{\mathrm{ab}}$ & 25,2 & $15,7^{\mathrm{ab}}$ & $8,2^{\mathrm{b}}$ \\
$200 \mathrm{~kg} / \mathrm{ha}$ & $552,7^{\mathrm{b}}$ & $114,2^{\mathrm{b}}$ & 25,2 & $15,9^{\mathrm{a}}$ & $8,7^{\mathrm{a}}$ \\
$250 \mathrm{~kg} / \mathrm{ha}$ & $605,3^{\mathrm{a}}$ & $96,8^{\mathrm{c}}$ & $25,1^{\mathrm{ns}}$ & $14,7^{\mathrm{b}}$ & $8,3^{\mathrm{b}}$ \\
\hline $\mathrm{CV}(\%)$ & 9,5 & 13,7 & 10,3 & 15,2 & 16,1 \\
F tính & $*$ & $*$ & $n \mathrm{~ns}$ & $*$ & $*$ \\
\hline
\end{tabular}

${ }^{1}$ NSLT: năng suất lý thuyết; NSTT: năng suất thực thu. Trong cùng một nhóm trung bình, những giá trị có cùng kí tự khác biệt không có ý nghĩa về mặt thống kê, ns: khác biệt không có ý nghĩa trong thống kê; *: khác biệt có ý nghĩa ở mức $\alpha=0,05 ; * *$ : khác biệt rất có ý nghĩa ở mức $\alpha=0,01$.

Bảng 2. Hiệu quả kinh tế của các mật độ sạ giống lúa MT10, vụ Đông Xuân 2015/2016 tại Ninh Sơn

\begin{tabular}{clcccc}
\hline \multirow{2}{*}{ STT } & \multirow{2}{*}{ Nội dung } & \multicolumn{4}{c}{ Mật độ sạ $(\mathrm{kg} / \mathrm{ha})$} \\
\cline { 3 - 6 } & & 120 & 160 & 200 & 250 \\
\hline I & Công lao động & 10.400 & 10.500 & 10.500 & 10.500 \\
II & Chi phí VTNN & 11.165 & 11.645 & 12.125 & 12.725 \\
III & Tồng thu (1.000 đ) & 40.280 & 43.460 & 46.110 & 43.990 \\
& Năng suất (tấn/ha) & 7,6 & 8,2 & 8,7 & 8,3 \\
& Giá bán (1.000 đồng/kg) & 5,3 & 5,3 & 5,3 & 5,3 \\
IV & Lợi nhuận (III-I-II) & 18.715 & 21.315 & 23.485 & 20.765 \\
\hline
\end{tabular}

Đơn vị tính: 1.000 đồng.

\subsection{2. Ảnh hưởng của mật độ sạ đến hiệu quả kinh tế}

Đánh giá hiệu quả kinh tế của các công thức gieo sạ với mật độ khác nhau trên giống lúa mới MT10 cho thấy, công thức 3 (gieo $200 \mathrm{~kg}$ giống/ha) có tổng thu cao nhất, đạt 46.110.000 đồng, công thức gieo với mật độ 120 kg giống/ha có tổng thu thấp nhất (đạt 40.280.000 đồng). Công thức 3 cho lợi nhuận đạt cao nhất, đạt 23.485.000 đồng/ha (Bảng 2).

Như vậy, trong điều kiện gieo trồng tại Ninh Thuận, giống lúa mới MT10 nên gieo với lượng $200 \mathrm{~kg}$ giống/ha cho năng suất và hiệu quả cao nhất. Tuy nhiên, kết quả nghiên cứu này là mâu thuẫn so với chủ trương "ba phải, năm giảm" trong sản xuất lúa hiện nay. Điều này có thể giải thích là trong điều kiện thí nghiệm tại Ninh Thuận, giống lúa MT10 có khả năng đẻ nhánh kém nên cần gieo sạ với mật độ cao để đảm bảo số bông/đơn vị diện tích và đảm bảo năng suất lúa.

\subsection{Nghiên cứu xác định liều lượng phân đạm thích hợp cho giống lúa MT10}

Đối với các giống lúa năng suất cao, lượng chất dinh dưỡng cây trồng lấy đi nhiều, vì vậy cần bổ sung đầy đủ các loại chất dinh dưỡng, nguyên tố đa, trung và vi lượng; trong đó, đạm là chất dinh dưỡng quan trọng nhất. Để sản xuất một tấn thóc, cây lúa cần khoảng 20 kg N. Khi năng suất lúa tăng thì lượng đạm cần thiết để hình thành năng suất sẽ tăng lên (Nguyen, 2006).

\subsection{1. Ảnh hưởng của liều lượng phân đạm đến yếu tố cấu thành năng suất và năng suất}

Kết quả Bảng 3 cho thấy, số bông hữu hiệu/khóm của các liều lượng bón phân đạm khác nhau trên giống lúa mới MT10 là không sai khác nhau, dao động từ 5,6-5,7 bông/khóm.

Số hạt chắc/bông: Công thức bón 140 và $160 \mathrm{~kg}$ N/ha cho số hạt chắc/bông là cao nhất, sai khác có ý nghĩa so với các công thức khác. Công thức bón với lượng $100 \mathrm{~kg}$ N/ha có số hạt chắc/bông 
Bảng 3. Ảnh hưởng của liều lượng phân đạm đến năng suất của giống lúa MT10, vụ Hè Thu 2016 tại Ninh Sơn, Ninh Thuận ${ }^{1}$

\begin{tabular}{lcccccc}
\hline Nghiệm thức & $\begin{array}{c}\text { Số bông } \\
\text { hữu hiệu/khóm } \\
\text { (bông) }\end{array}$ & $\begin{array}{c}\text { Số hạt } \\
\text { chắc/bông } \\
\text { (hạt) }\end{array}$ & $\begin{array}{c}\text { Tỷ lệ } \\
\text { hạt lép } \\
(\%)\end{array}$ & $\begin{array}{c}\text { Khối lượng } \\
1.000 \text { hạt } \\
\text { (gam) }\end{array}$ & $\begin{array}{c}\text { NSLT } \\
\text { (tấn/ha) }\end{array}$ & $\begin{array}{c}\text { NSTT } \\
\text { (tấn/ha) }\end{array}$ \\
\hline $100 \mathrm{~kg} \mathrm{~N} / \mathrm{ha}$ & $5,6^{\mathrm{ns}}$ & $122,0^{\mathrm{b}}$ & $8,3^{\mathrm{b}}$ & $26,2^{\mathrm{ns}}$ & $8,9^{\mathrm{b}}$ & $5,6^{\mathrm{b}}$ \\
$120 \mathrm{~kg} \mathrm{~N} / \mathrm{ha}$ & 5,7 & $123,2^{\mathrm{b}}$ & $9,0^{\mathrm{a}}$ & 26,1 & $9,1^{\mathrm{b}}$ & $5,8^{\mathrm{b}}$ \\
$140 \mathrm{~kg} \mathrm{~N} / \mathrm{ha}$ & 5,6 & $132,0^{\mathrm{a}}$ & $8,9^{\mathrm{a}}$ & 26,1 & $9,7^{\mathrm{a}}$ & $6,4^{\mathrm{a}}$ \\
$160 \mathrm{~kg} \mathrm{~N} / \mathrm{ha}$ & 5,7 & $132,8^{\mathrm{a}}$ & $7,7^{\mathrm{c}}$ & 26,2 & $10,0^{\mathrm{a}}$ & $6,5^{\mathrm{a}}$ \\
\hline $\mathrm{CV}(\%)$ & 7,2 & 11,8 & 13,2 & 10,6 & 14,3 & 15,8 \\
$\mathrm{~F} \mathrm{tính}$ & $\mathrm{ns}$ & $*$ & $*$ & $*$ & $*$ & $*$ \\
\hline
\end{tabular}

${ }^{1}$ NSLT: năng suất lý thuyết; NSTT: năng suất thực thu. Trong cùng một nhóm trung bình, những giá trị có cùng kí tự khác biệt không có ý nghĩa về mặt thống kê, ns: khác biệt không có ý nghĩa trong thống kê; *: khác biệt có ý nghĩa ở mức $\alpha=0,05 ; * *$ : khác biệt rất có ý nghĩa ở mức $\alpha=0,01$.

Bảng 4. Hiệu quả kinh tế của các liều lượng phân đạm trên giống lúa MT10, vụ Hè Thu 2016 tại Ninh Sơn

\begin{tabular}{clcccc}
\hline \multirow{2}{*}{ STT } & \multirow{2}{*}{ Nội dung } & \multicolumn{3}{c}{ Liều lượng phân đạm $(\mathrm{kg} / \mathrm{ha})$} \\
\cline { 3 - 6 } & & $100 \mathrm{~kg} \mathrm{~N} / \mathrm{ha}$ & $120 \mathrm{~kg} \mathrm{~N} / \mathrm{ha}$ & $140 \mathrm{~kg} \mathrm{~N} / \mathrm{ha}$ & $160 \mathrm{~kg} \mathrm{~N} / \mathrm{ha}$ \\
\hline I & Công lao động & $10.500,0$ & $10.500,0$ & $10.500,0$ & $10.500,0$ \\
II & Chi phí VTNN & $9.935,6$ & $10.290,0$ & $10.644,5$ & $10.998,1$ \\
III & Tồng thu (1.000 đ) & $29.680,0$ & $30.740,0$ & $33.920,0$ & $34.450,0$ \\
& Năng suất (tấn/ha) & 5,6 & 5,8 & 6,4 & 6,5 \\
& Giá bán (1.000 đ/kg) & 5,3 & 5,3 & 5,3 & 5,3 \\
IV & Lợi nhuận (III-I-II) & $9.244,5$ & $9.950,0$ & $12.775,6$ & $12.951,9$ \\
\hline
\end{tabular}

Đơn vị tính: 1.000 đồng.

thấp nhất.

Tỷ lệ hạt lép: công thức bón $120 \mathrm{~kg} \mathrm{~N} /$ ha và $140 \mathrm{~kg} \mathrm{~N} /$ ha có tỷ lệ hạt lép cao nhất, sai khác có ý nghĩa với các công thức khác. Công thức 160 kg N/ha có tỷ lệ hạt lép thấp nhất.

Năng suất lý thuyết: Giống lúa MT10 là giống có tiềm năng năng suất cao, sinh trưởng phát triển mạnh, sinh khối lớn nên công thức bón 140 $\mathrm{kg} \mathrm{N} /$ ha và $160 \mathrm{~kg} \mathrm{~N} /$ ha cho năng suất lý thuyết cao nhất, sai khác có ý nghĩa thống kê với các công thức khác. Công thức này cũng cho năng suất thực thu cao nhất. Đây cũng là hai công thức bón phân có năng suất thực thu cao nhất.

Qua đánh giá hiệu quả kinh tế (Bảng 4) của các công thức phân bón trên giống lúa mới MT10 cho thấy, công thức 3 (bón $140 \mathrm{~kg} \mathrm{~N} / \mathrm{ha}$ ) và công thức 4 (bón $160 \mathrm{~kg} \mathrm{~N} /$ ha) có tổng thu và lợi nhuận cao nhất, tổng thu đạt 33,92 - 34,45 triệu đồng, lợi nhuận đạt từ 12,77 - 12,95 triệu đồng/ha .

Như vậy, liều lượng phân bón thích hợp cho giống lúa MT10 là $140 \mathrm{~N}+60 \mathrm{P}_{2} \mathrm{O}_{5}+70 \mathrm{~K}_{2} \mathrm{O}$.

\section{Kết Luận và Đề Nghị}

\subsection{Kết luận}

Qua nghiên cứu mật độ sạ và liều lượng đạm cho giống lúa MT10 tại Ninh Thuận có thể kết luận rằng:

Mật độ gieo sạ thích hợp cho giống lúa MT10 là $200 \mathrm{~kg} / \mathrm{ha}$ sẽ cho năng suất và hiệu quả kinh tế cao nhất, năng suất đạt 8,7 tấn/ha, lợi nhuận đạt cao nhất, đạt 23.485.000 đồng/ha.

Liều lượng phân đạm thích hợp cho giống MT10 trong điều kiện thí nghiệm cấy ở Ninh Thuận là $140 \mathrm{kgN} /$ ha sẽ cho năng suất và hiệu quả kinh tế cao nhất, năng suất đạt 6,4 tấn/ha, lợi nhuận thu được 12,77 triệu đồng/ha.

\subsection{1. Đề nghi}

Giống lúa MT10 gieo trồng trong điều kiện của Ninh Thuận nên sạ thẳng với lượng giống $200 \mathrm{~kg} / \mathrm{ha}$. Nếu nông dân có đủ điều kiện: mặt 
bằng tốt, sử dụng giống xác nhận, chủ động nước, phòng trừ cỏ dại thật tốt thì có thể giảm lượng giống gieo sạ xuống còn 80 kg/ha (MARD, 2003).

Áp dụng liều lượng phân đạm thích hợp cho giống MT10 là 140 kg N/ha.

\section{Tài Liệu Tham Khảo (References)}

Doan, H. V. (2014). Seeding density, phosphate level and handling with Dasvila for rice to high yield and economic efficiency. An Giang University Journal of Science, 3(2), 38-42.

MARD (Ministry of Agriculture and Rural Development). (2014). Decision No. 109/QD-TT-CLT dated April 04, 2014 of the Minister of MARD on the recognition of new varieties of agricultural plant species. Ha Noi, Vietnam: MARD Office.
MARD (Ministry of Agriculture and Rural Development). (2003). 10TCN 216:2003-Field effect of fertilizers for crop yield and quality of agriculture products. Ha Noi, Vietnam: MARD Office.

Nguyen, H. V. (2006). Rice handbook: Intensive high-yield rice. Ha Noi, Vietnam: Labor Publishing House.

Nguyen, D. N. (2008). Rice syllabus. Can Tho, Vietnam: Can Tho Publishing House.

Tran, M. V. (2015). Selection of short-term rice varieties and intensive techniques of production in the South Central Coast of Vietnam (Unpublished doctoral dissertation). Hue University, Vietnam. 